Brit. J. prev. soc. Med. (1966), 20, 9-14

\title{
THE AGE AT MENARCHE
}

BY

\author{
P. E. BROWN
}

From the Department of Preventive Medicine and Public Health, University of Sheffield

The menarche is the most obvious and the most easily ascertained sign of puberty in girls. No parallel event occurs in boys. For this reason comparative studies on the average age at onset of menstruation, such as those given by Tanner $(1955,1961,1962)$, provide the greater part of the evidence in support of the view that children are maturing earlier than they used to. Skeletal measurements, extensively used by Morant (1948) and Martin (1949), have proved less conclusive (Boyne and Leitch, 1954).

Menstruation studies, however, have their disadvantages. Their value as a means of estimating the secular trend in the age of maturity must depend on the assumption that the age at the menarche, the age of sexual maturity, and maturation in general are intrinsically related. Only if this is true is it safe to use changes in the age at the menarche as a measure of changes in other developmental factors or in maturation as a whole.

Certainly, this assumption provides, on the whole, the simplest explanation of the known facts. Growth and development follow such a regular pattern that some built-in co-ordinating mechanism seems almost indispensable. Endocrine and neuro-humoral links have been demonstrated and account for the sequence of events in many phases of development. A general maturity factor has been extracted by means of factorial analysis (Nicolson and Hanley, 1953).

On the other hand, the all-embracing concept of maturation raises difficulties. If the rate of maturation is controlled by a single biological pace-maker, the problem is to show how this pace-maker can be made to change its setting and produce a secular trend. If, as Tanner (1961) believes, "the secular trend, both in earlier maturation and in greater size, is one of the most considerable phenomena of human biology at present, and has, into the bargain, a host of medical, educational, and sociological consequences", then it must be admitted that no comparable phenomenon readily comes to mind that is not the outcome of a prolonged evolutionary process.

It is evident that Tanner has anticipated criticisms of this kind. He emphasizes the regularity of the secular trend and its similarity in different countries, both indications of the biological nature of the change. He discounts explanations which rely on ordinary environmental agents, such as improved nutrition, poor social conditions, and increased psycho-sexual stimulation. He seems to prefer semi-cosmic causes: alterations in world temperature, the breaking down of genetic isolates, and the selective effect of the reduction of bacterial infections.

There is little factual evidence to support these suggestions and the cause of the secular trend remains unsolved. Further study is obviously required and one hitherto neglected source of information is the frequency distribution of the age at menarche. Unfortunately, frequency distributions have rarely been given in detail, particularly in the 19th century. The following, however, have been obtained and are presented for comparison:

(1) Kiil (1953). Oslo school-girls in 1928 and 1952.

(2) Waddy (1846). Birmingham maternity hospital patients in the period covering approximately 1830-45.

(3) Unpublished data from a survey of elderly persons in Sheffield (Hobson and Pemberton, 1955). In 1949-51, 257 women between the ages of 60 and 85 were questioned as to the age at menarche, the data thus refer to the period around $\mathbf{1 8 9 0 .}$

(4) Wilson and Sutherland (1949). Oxford school-girls in city and county in 1949.

(5) Unpublished data obtained during a thyroid survey in the West Riding of Yorkshire in 1962. 685 girls between the ages of 15 and 19 years were questioned about the year and month in which they started 
menstruating. During the same survey a sample of the 369 girls from the East of Scotland were similarly questioned.

\section{RESUlTS}

The percentage of girls in each of the surveys who had started menstruating by the time they had reached a given birthday is shown in Table $I$, which also gives the average age at onset and the range of ages. It should be noted that the proportion of girls menstruating before their 10th and 11th birthdays is much the same in all the surveys. The secular trend does not become fully evident until the position at the 14th birthday is studied. Thus the range of ages starts at the 9th or 10th year in all the surveys, and the differences are seen at the end of the range which varies from 16 to 23 years. The two Oslo series are compared in Fig. 1 and the Birmingham, Sheffield, Oxford City, and West Riding series in Fig. 2 (opposite).

In the majority of surveys the girls were asked to recall the age at which they began menstruating, but in the Norwegian surveys groups of girls of different ages were asked whether or not they had started. Each age group, therefore, represents a separate sample of girls and the apparent falling off of the percentage menstruating after the age of 16 in the 1952 Oslo data is presumably due to sampling error. In the Sheffield series the period of recall was, of course, in the region of 50 years. Of 257 questioned, 236 gave positive replies, twenty said they could not remember, and one said she had never menstruated.

The average age at menarche in sixteen English surveys between 1832 and 1933 is given in Fig. 3 (opposite).

These are based on data provided by Backman (1948). The six series published before 1850 comprised 8,831 individuals and give a weighted mean of $15 \cdot 7$ years. Between 1850 and 1871 there were five series comprising 7,378 individuals with a weighted mean of $15 \cdot 3$ years. Between 1875 and 1901 there were four series comprising 2,400 individuals, with a mean of $15 \cdot 3$ years. The 1933 series comprised 10,119 individuals with a mean of $15 \cdot 0$ years. Backman's data for France and Germany are shown diagrammatically in Fig. 4 (opposite).

\section{Discussion}

The most obvious difference in the eight series shown in Table $I$ is in the range of ages over which menstruation started. In some of the later series all the girls had started by 17 or 18 years. In the 19th century series the onset for some individuals was delayed until 20 years or more. No comparable differences are found at the lower end of the range. A characteristic of the change which has taken place in the last 100 years is, therefore, the disappearance of individuals with a late onset of menstruation and a consequent closing up of the distribution in the direction of the lower end of the range. There is no evidence that the lower limit of the range itself has extended downwards.

The same tendency is shown in Fig. 2. If the pair of graphs representing the two 19th century series is compared with the pair representing the two 20th

TABLE I

PERCENTAGE OF GIRLS MENSTRUATING BY A GIVEN BIRTHDAY

\begin{tabular}{|c|c|c|c|c|c|c|c|c|c|}
\hline \multirow{2}{*}{\multicolumn{2}{|c|}{ Birthday }} & 1845 & 1890 & 1928 & 1949 & 1949 & 1952 & 1962 & 1962 \\
\hline & & Birmingham & Sheffield & Oslo & Oxford 1 & Oxford 2 & Oslo & Scotland & $\begin{array}{c}\text { Yorkshire } \\
\text { West Riding }\end{array}$ \\
\hline $\begin{array}{r}9 \\
10 \\
11 \\
12 \\
13 \\
14 \\
15 \\
16 \\
17 \\
18 \\
19 \\
20 \\
21 \\
22 \\
23\end{array}$ & & $\begin{array}{r}\overline{0.2} \\
0.5 \\
2.9 \\
10.3 \\
24.2 \\
45.1 \\
63.6 \\
80.4 \\
91.2 \\
98.1 \\
99.7 \\
100.0 \\
=\end{array}$ & $\begin{array}{r}\overline{0.4} \\
1.7 \\
6 \cdot 3 \\
16.9 \\
40.5 \\
59 \cdot 1 \\
72 \cdot 6 \\
86 \cdot 1 \\
90 \cdot 7 \\
96 \cdot 2 \\
97.5 \\
98.3 \\
99 \cdot 2 \\
99.6\end{array}$ & $\begin{array}{c}= \\
\overline{0.3} \\
2.5 \\
15.4 \\
44.8 \\
74.4 \\
95.5 \\
98.3 \\
98.9 \\
100.0 \\
= \\
=\end{array}$ & $\begin{array}{r}\overline{0.2} \\
0.6 \\
5.6 \\
24.8 \\
64.6 \\
90.8 \\
95.5 \\
100.0 \\
= \\
= \\
= \\
=\end{array}$ & $\begin{array}{c}= \\
\overline{1} .0 \\
7.5 \\
29.6 \\
63.3 \\
89.4 \\
95.4 \\
98.2 \\
100.0 \\
= \\
= \\
=\end{array}$ & $\begin{array}{r}\overline{0 \cdot 4} \\
2 \cdot 0 \\
12 \cdot 3 \\
41 \cdot 2 \\
74 \cdot 7 \\
93 \cdot 2 \\
97 \cdot 1 \\
96 \cdot 3 \\
95 \cdot 1 \\
94 \cdot 3 \\
= \\
= \\
=\end{array}$ & $\begin{array}{c}\overline{ } \\
\overline{5.0} \\
17.2 \\
44.6 \\
79.8 \\
95.9 \\
99.7 \\
100.0 \\
= \\
= \\
=\end{array}$ & $\begin{array}{r}\overline{0.3} \\
3.9 \\
20.0 \\
55.3 \\
84.9 \\
96.9 \\
99.4 \\
99.9 \\
100.0 \\
= \\
= \\
=\end{array}$ \\
\hline No. of Girls $\quad$. & . & 623 & 237 & 9,169 & 572 & 766 & 11,618 & 369 & 685 \\
\hline Average Age (yrs) & $\ldots$ & $15 \cdot 3$ & $14 \cdot 8$ & $14 \cdot 2$ & $13 \cdot 6^{*}$ & $13 \cdot 6^{*}$ & $13 \cdot 4$ & $13 \cdot 1$ & $12 \cdot 9$ \\
\hline Range (yrs) & $\ldots$ & 11 & $14+$ & 8 & 7 & 7 & $10+$ & 6 & 8 \\
\hline $\begin{array}{ll}\text { Lower Limit } & \ldots \\
\text { Upper Limit } & \ldots\end{array}$ & $\therefore$ & $\begin{array}{r}9 \\
20\end{array}$ & $23+$ & $\begin{array}{l}10 \\
18\end{array}$ & $\begin{array}{r}9 \\
16\end{array}$ & $\begin{array}{l}10 \\
17\end{array}$ & $99+$ & $\begin{array}{l}10 \\
16\end{array}$ & $\begin{array}{r}9 \\
17\end{array}$ \\
\hline
\end{tabular}

- Median score 


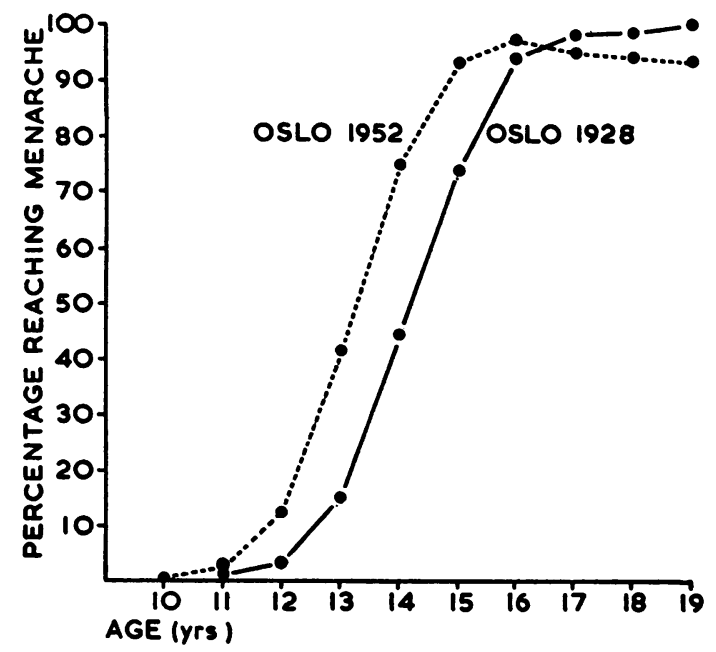

FIG. 1.-Percentage of girls menstruating at a given age in Oslo, 1928 and 1952 (Kiil, 1953).

century series, it will be seen that the origins are almost the same but that the slopes of the two pairs are very different. As the slope is determined by the dispersion of observations, it follows that the dispersion was greater in the 19th century than it is now. The 19th century series are made up in part of girls who menstruated as early as modern girls and in part of girls who menstruated much later.

The two Oslo series (Fig. 1), however, present an entirely different picture. The curve representing the 1952 series is similar to that representing the 1928

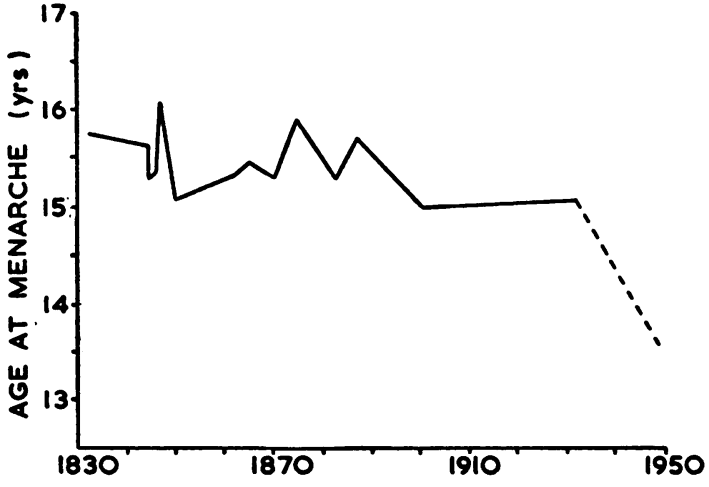

FIG. 3.-Average age at menarche in England in the 19th and 20th centuries, from data provided by Backman (1948) and extended to include the 1949 average given by Wilson and Sutherland (1949).

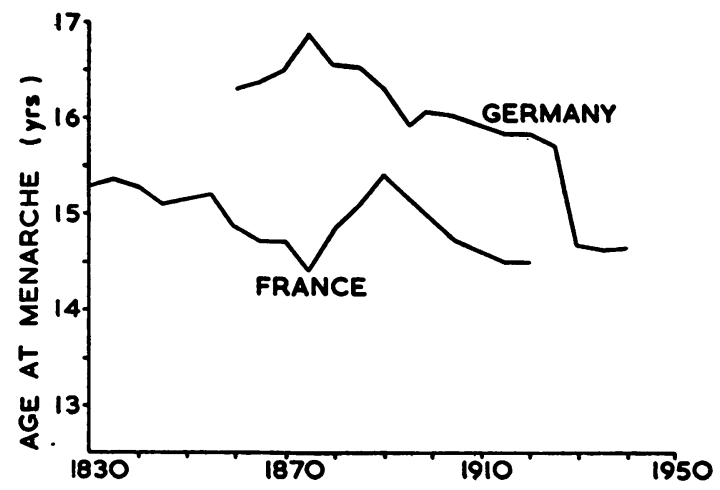

Fig. 4.-Average age at menarche in Germany and France in the 19th and 20 th centuries, from data provided by Backman (1948).

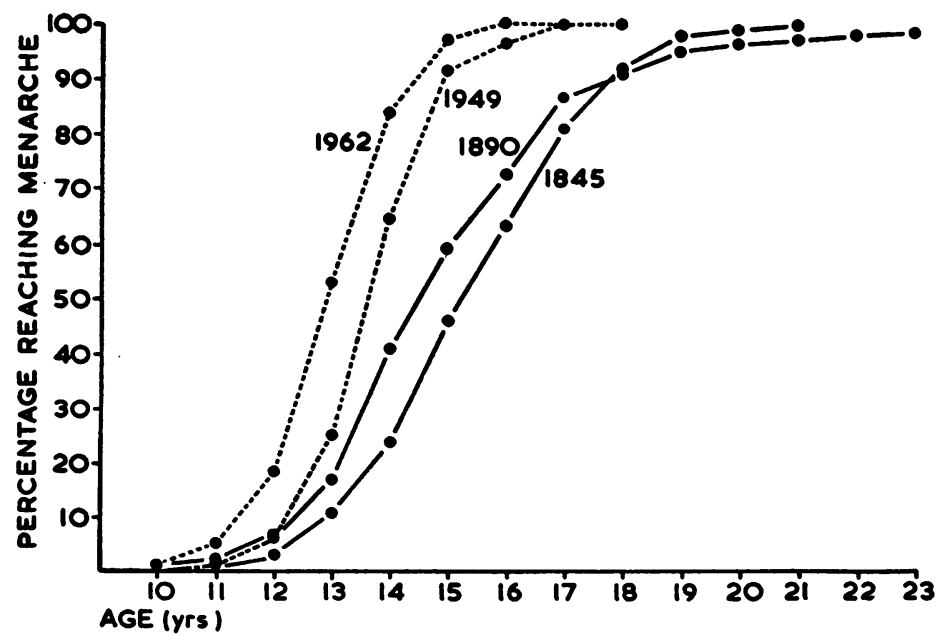

FIG. 2.-Percentage of girls menstruating at a given age in England, 1845 (Waddy, 1846), 1890 and 1949 (Wilson and Sutherland, 1949), and 1962. 
series but appears to have shifted bodily along the horizontal axis without changing its slope. A similar difference is seen between the individual members of the two pairs of graphs shown in Fig. 2.

It is difficult to escape the conclusion that two types of change have occurred in the age at menarche. In the one, part of the population has advanced considerably and the rest scarcely at all. In the other, the shift appears to have affected the whole population equally, as though every girl had taken several months off her age at onset of menstruation. The first type of change is compatible with the theory that the advance in the average age at menarche is due to the elimination of delaying diseases, such as tuberculosis and iron deficiency. The second type is more in keeping with Tanner's concept of a fundamental biological phenomenon. But the most significant feature of the two sets of results is the suggestion that two different processes have been going on at the same time.

One way out of the difficulty is to discard one or other set of data on the grounds of its unreliability. But which set? To accept only those data which satisfy the strictest criteria is to confine the inquiry to modern, highly-developed communities, in which differences in the age as menarche are known to be small. It seems unreasonable to embark on a historical investigation in the first place and then give the unreliability of certain data as the reason for discarding inconvenient hypotheses.

In fact, observations from another source support the contention that more than one process is involved in the declining age at menarche. The data provided by Backman (1948) for England, France, and Germany are reproduced in Figs 3 and 4. These contrast with the more regular trends presented by Tanner (1962) for Finland, Sweden, Norway, and the USA, which were selected because they were based on "the most extensive and best-reported data". Backman's view is this: "In England, Norway, and Finland, the advancement of puberty developed in a uniform and continuous way; in Germany, France, Denmark, and Sweden, on the other hand, the change was at times quicker, at times slower; in France it even showed retardation for 20-25 years between a preceding and a subsequent period of advancement". "The war of 1870-1, and the revolutionary movements in France which followed upon it, exercised in France a retarding influence on the onset of menstruation." The age at onset in Norway (17.4 years) in the mid-19th century he regards as "strikingly late" in comparison with other contries, although some writers have assumed that an equally late onset was then the rule in Great Britain also (Carstairs, 1963).
When everything is taken into account, therefore, there is little to show that the decline in the age at the menarche is characteristically uniform and universally consistent. Indeed, what regularities there are can be adequately explained as the smoothing effect of several influences all proceeding in more or less the same direction. And once the idea of a uniform, universal, and inexorable change is abandoned, we can see our way out of what appears to be an aetiological impasse.

As far as the age at menarche is concerned, this means that more than one set of causes can be considered. The unduly delayed onset of menstruation in a proportion of the population in the 19th century can be attributed to diseases such as tuberculosis and nutritional deficiencies. These were known to be prevalent and it is scarcely conceivable that they were without influence. The general shift in the population which, in the two Oslo series, for example, suggests that every girl is now claiming an earlier menarche than her predecessors requires an alternative explanation and the most promising seems to be a change in the psycho-sexual environment. Tanner (1961) dismisses this for two reasons: one is that the downward trend proceeded at its constant rate of 4 months per decade throughout the "Victorian" era (when, presumably, the psychosexual environment was stable), the other is that Oslo school-girls at co-educational schools do not differ, as regards the age at menarche, from those at schools for girls only. But the "Victorian" era belongs to England where the downward trend could not have been more than one month per decade. The rate of 4 months per decade is derived from Scandinavia which has a recognizable cultural tradition of its own. As for the Oslo school-girls, it would be surprising if the psycho-sexual environment of any of them was contained within the classroom and the playground.

In fact, the psycho-social environment may very well operate in more than one way. For example, it may affect the recall of those questioned some time after the event. In the Sheffield series, after 50 years, all but twenty of 257 women questioned were able to give an exact age at onset. Is this fact, or is it fact modified by a life-time's exposure to changing cultural pressures? Certainly, the average age of this group is considerably lower than that given by Backman (1948) for the same period. One explanation of the difference is that Backman's subjects were questioned while they were still young and before their memories had been influenced by 20 th century values. On the other hand, it may be that psychological or cultural pressures retard or accelerate a triggering-off process and determine when a girl who is otherwise sexually mature produces her first show 
of blood. Both these factors are at present under investigation in a follow-up study.

Some light on whether the first menstrual period always occurs at the same stage of physical and sexual development was provided by Nicolson and Hanley (1953), who used factorial analysis to investigate ways of assessing progress along the "hypothetical maturation continuum" and found a general factor with high loadings in each of their measures of maturation. They concluded that earliness or lateness on a given measure at a particular age level was a function of the general maturational status at the time. The index with the highest loading $(\cdot 967)$ was the age on reaching 90 per cent. of mature height, which gave a correlation with the age at menarche of $r=\cdot 861$.

The extraction of a general factor does not, of course, establish the existence of a corresponding general maturation mechanism. The correlation matrix can equally well be explained by assuming as many factors as there are pairs of variables. In fact, there is evidence that maturation in height does not nowadays bear the same relationship to the age at menarche that it once did. From Nicolson and Hanley's data a regression equation can be derived for expected age at menarche for any given age on reaching 90 per cent. of mature height:

Age at menarche $=1.076 \times$ Age on reaching 90 per cent. mature height +0.54 years.

Data provided by Galton (1883) from his Anthropometric Survey allow the age on reaching 90 per cent. of mature height to be calculated for three social groups. These are given in Table II, together with the estimated age at menarche based on the regression equation and with the higher 5 per cent. confidence limit. It will be seen that these limits are below contemporary estimates of the age at menarche. Thus the relationship between age at menarche and other indices of maturation cannot be regarded

TABLE II

ESTIMATES OF THE MEAN AGE AT MENARCHE FOR THE YEAR 1883, USING DATA FROM THE ANTHROPOMETRIC SURVEY (GALTON, 1883) AND A REGRESSION EQUATION DERIVED FROM NICOLSON AND HANLEY (1953)

\begin{tabular}{|c|c|c|c|c|}
\hline \multirow[b]{2}{*}{ Estimate } & \multirow{2}{*}{$\begin{array}{c}\text { Whole } \\
\text { Popula- } \\
\text { tion }\end{array}$} & \multicolumn{3}{|c|}{ Social Class } \\
\hline & & $\begin{array}{l}\text { I. Pro- } \\
\text { fessional }\end{array}$ & $\begin{array}{l}\text { II. Com- } \\
\text { mercial } \\
\text { (Town) }\end{array}$ & $\begin{array}{c}\text { III. } \\
\text { Artisan } \\
\text { (Town) }\end{array}$ \\
\hline Mature Adult Height (in.) & $62 \cdot 7$ & $63 \cdot 4$ & $62 \cdot 5$ & $61 \cdot 1$ \\
\hline $\begin{array}{l}\text { Age (yrs) at attaining } 90 \\
\text { per cent. Mature Height } \\
\text { Estimated Age at Menarche } \\
\begin{array}{llll}\text { (yrs) } & . . & . & .\end{array}\end{array}$ & $\begin{array}{l}12 \cdot 9 \\
14 \cdot 4\end{array}$ & $\begin{array}{l}12 \cdot 3 \\
13 \cdot 8\end{array}$ & $\begin{array}{l}12 \cdot 7 \\
14 \cdot 2\end{array}$ & $\begin{array}{l}13 \cdot 0 \\
14 \cdot 5\end{array}$ \\
\hline $\begin{array}{ccc}\text { Upper Confidence } & \text { Limit } \\
\text { (5 per cent.) } & . & .\end{array}$ & $14 \cdot 9$ & $14 \cdot 3$ & $14 \cdot 7$ & $15 \cdot 0$ \\
\hline
\end{tabular}

as invariable and the assertion of Kiil (1939) that "it goes without saying" that present-day relationships also hold good for earlier times cannot be accepted.

On the present evidence, therefore, it is by no means certain that the changes which have occurred in the age at menarche are the outcome of any fundamental biological transformation. It is not even certain that these changes are the result of a single aetiological factor. Several sets of causes may be involved. One of them may be primarily associated with physical development, one with mental development, and another with social development. If this view is accepted the major difficulties of the unitary hypothesis can be avoided.

\section{Summary aNd CoNClusions}

(1) The value of the age at menarche as an index of the secular trend towards earlier maturity depends on the nature of its relationship with the other indices of maturation.

(2) The view of Tanner and others is that maturation is a single organic process, controlled, apparently, by a central pace-maker. The secular trend is thought of primarily as a biological phenomenon, with biological and hereditary origins, which educationists and sociologists must submit to.

(3) Examination of the frequency distributions of the age at onset of menstruation in groups of girls studied in the 19th and 20th centuries, however, raises doubts as to the correctness of this view. The average age at menarche seems to result from two kinds of change in the frequency distribution. One is associated with the reduction in the proportion of girls in whom menarche is unduly delayed, which could reflect the decreasing incidence of chronic infections and nutritional deficiencies. The other is more general in nature, affecting all girls more or less equally.

(4) The regularity of the secular trend in Finland, Sweden, Norway, and the USA-on which the general biological theory largely depends-is, moreover, not repeated in England, France, and Germany where local and temporary factors seem important.

(5) It is not disputed that the lowering of the average age at menarche is of considerable interest, but until its biological, psychological, and sociological causes have been further unravelled its significance remains uncertain. As yet, there seems to be little justification for regarding it as "one of the most considerable phenomena of human biology". 


\section{REFERENCES}

Backman, G. (1948). Acta anat. (Basel), 4, 421.

Boyne, A. W., and Leitch, I. (1954). Nutr. Abstr. Rev., $24,255$.

Carstairs, G. M. (1963). “This Island Now", p. 50. (BBC Reith Lectures, 1962). Hogarth Press, London.

Galton, F., and 14 others (1883). "Report of the 53rd Meeting of the British Association", p. 253. Publ. 1884.

Hobson, W., and Pemberton, J. (1955). "The Health of the Elderly at Home". Butterworth, London.

Kiil, V. (1939). Skr. norske Vidensk.-Acad., I Mat.-nat. Kl., 6,175 . (1953). Statist Kvart., 43, 84.
Martin, W. J. (1949). "The Physique of Young Adult Males". Med. Res.Coun. Mem. No. 20. HMSO, London. Morant, G. M. (1948). Biometrika, 35, 368.

Nicolson, A. B., and Hanley, C. (1953). Child Dev., 24, 3.

Tanner, J. M. (1955). "Growth at Adolescence", ist ed. Blackwell, Oxford. (1961). "Education and Physical Growth". University of London Press.

(1962). Growth at Adolescence, 2nd ed. Blackwell, Oxford.

Waddy, J. M. (1946). Lancet, 1, 673.

Wilson, D. C., and Sutherland, I. (1949). Brit. med. J., 2,130 . 